Hugo Acevedo

\title{
Emilio Becher
}

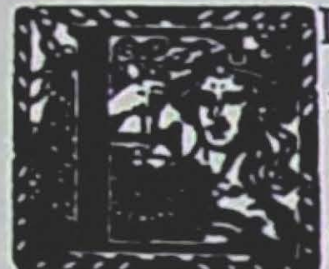

L hombre que sólo puede mostrar pergaminos de altura moral es un ser respetable. El que sólo bondades de la inteligencia luce, pero con falta de aquéllos, es un ser temible. El que presenta, unidos, los dos casos, es un ser maravilloso. Emilio Becher era de éstos.

No guardamos recuerdos aislados de Becher; todo él está presente en nuestro pensamiento y en nuestro corazón: única forma de recordarlo y de amarlo, pues Becher, su talento extraño, profundo y brillante, su bondad más extraña aún, su dolor de vida, pertenecía al rango de los seres a cuya estimación se llega no por simple sentimiento ni por simple intención, sino mediante la unión de ambos en un análisis severo y grave. La humildad de Becher lo exige.

Así se opera el milagro de recordar y amar a un hombre cuya vida pasó antes de que la nuestra aflorara. En efecto, de la figura de Becher sólo conocemos un retrato: alta, luminosa la frente, fuerte y bella, tan impresionante, que para nosotros el rostro de Becher es la identificación de una frente; y el trazo de las cejas, la lejanía lúcida de la mirada, el mentón delicado y voluntarioso son el complemento cabal de una cabeza donde la vida encontró, quizás, demasiada amplitud. Esto es, cuanto nos quede del Becher físico. Después, lo valedero, el espíritu: tenemos la descripción de su existencia por parte de quienes se honraron con su amistad, nombres - algunos ilus- 
tres- de la literatura argentina, como Ricardo Rojas, Alberto Gerchunoff, Leopoldo Lugones; y tenemos sus artículos. Porque Emilio Becher fué periodista. Fué, sin duda, mucho más que eso: no le cabe bien la denominación de un oficio cuya imagen esencial está dada por lo que no tiene pasado ni futuro, la fotografía, el renglón súbito, el comentario con fecha precisa e insalvable. Pero su obra, lo mejor de su obra, tuvo lugar en La Nación, de Buenos Aires, para cuyo personal, según lo atestigua Gerchunoff, Becher fué el más grande de los hermanos. De Becher sería más justo decir que también fué periodista.

Caín, Elogio de la pereza, La promesa de la serpiente, Franklin, son, entre otros, verdaderos ensayos donde la moral, la poesía, la mitología, la religión participan con la fluidez y la precisión diamantina que solamente una pluma de alto equilibrio, como la de Becher, puede otorgar. El estilo de Becher tiene una profundidad, una perfección, una sabiduría inigualadas en las letras de nuestro país.

Nosotros, sin embargo, no juzgamos sólo al pensador, al prosista, al erudito. Juzgamos, por sobre todas las cosas, al hombre culto. No estamos de acuerdo con la actitud mística o de parecida índole que ilustró Becher; no estamos tampoco de acuerdo con su crítica a la Era Industrial, que censuró duramente en Nuestra Civilización. Pero nos inclinamos con fervor amoroso ante el espectáculo de recta inteligencia que es la obra y hasta la vida de Becher. Consideramos al creador, al hombre, dentro de sus propósitos, de sus intenciones y sus realizaciones. Emilio Becher representa, de este modo, nuestro ideal humano. Entre su vida y sus anhelos, entre su decir y su hacer, entre su pensamiento y su acción, entre su espíritu y su voluntad, hay la unidad absoluta que recuerda el ejemplo, salvando odiosas comparaciones de inteligencia, de un Leonardo o un Beethoven.

En Emilio Becher el arte pierde los últimos resabios de vanidad - ligereza, para alcanzar la cima de la humildad. Escribe con sobriedad porque piensa con sobriedad, porque siente sobriamente. No es sentencioso: carece de la superstición profética para dictar adagios. 
Aun cuando habla de religión, su diáfana humildad se hace convincente a fuer de sincera. Y, sobre todo, de talentosa.

Pero Emilio Becher merece mucho más que este pobre discernimiento nuestro. No podemos referirnos a él con la frialdad objetiva propicia al análisis. No tratamos de ubicarlo, ni menos de catalogarlo. Lo tenemos aún tan cerca, tan visible, que toda actitud crítica se nos ahoga en la emoción. Somos sus peores discípulos.

$$
\text { * * }
$$

La juventud argentina no conoce a Emilio Becher. Este no es un fenómeno singular. La liberalidad de Becher, su independencia espiritual, es lo menos adecuado a nuestro época. Tal vez sea bueno que nuestra juventud pase sin conocerlo: siquiera así no será desvirtuado. Hombre sin castas -y la multitud, cuando se la endiosa, es una de ellas - no puede interesar a quien piensa con el corazón turbulento del enjambre. Becher pensaba con su propia inteligencia. Del mismo modo, tampoco llamará la atención de quien, para sentir, necesita del pobre concurso del laboratorio. Becher no era un científico; era un sabio. La época de Becher, aquella que conviene a su personalidad libre, es la época en que los hombres se esfuerzan por interpretar, no por repetir. Obtener la opinión de las propias fuerzas interiores suficientemente alimentadas, no de las enciclopedias conformadas al gusto oficial. Becher representa la democracia que todavía no hemos conocido: al César lo que es del César... No la democracia, falsa desde luego, del emparejamiento y la tabla rasa. No la democracia de la uniformidad, ni muchos menos de los uniformes. No la democracia del pueblo canonizado. En La promesa de la serpiente, uno de sus más bellos artículos, critica el cientifismo populachero de esta manera:

"Debemos agradecer la iniciativa que nos proporciona enciclopedias manuales y módicas. El diccionario es una obra po- 
pular. Resume los conocimientos humanos en nociones claras, breves y sentenciosas. Procura el mínimo de saber exigido por la instrucción obligatoria y universal. Vulgariza la erudición y hace más fácil la pedantería. Es el libro santo de la democracia. Nuestros antepasados leían la Biblia. Es la más admirable colección de cuentos históricos, místicos, amorosos y bélicos. Pero nuestra época la desdeña porque no es científica. El diccionario lo es".

Nuestros antepasados leían la Biblia... Hoy los autores más cotizados, entre nosotros, se llaman Agatha Christie, Cronin, Ellery Queen. Y el premio Nobel de Literatura lo recibe, no sabemos aún si honoris causa, el excelente político sir Winston Churchill. En cuanto a la Biblia... se lee, por cierto. Ahí están los Testigos de Jehová que recorren el mundo en envidiables aeroplanos presentándola corregida y aumentada y haciendo de ella una revisión casi estrictamente etimológica, aunque ninguno de ellos sea muy fuerte en idiomas, para tratar de convencernos de que al mundo le están contados los días y que es necesario ponerse bien con Dios y no preocuparse más de los problemas gremiales o de tipo afín. Esta es la mayor parte de nuestra literatura, de nuestra filosofía y de nuestra moral.

Bien está que Becher descanse mientras transcurre la ola de gregarismo. Nada incomodaría tanto a su memoria como una ubicación entre los literatos predominantes de hoy, aunque no sean periodistas ni políticos. Becher está reservado para las inteligencias que juzgan la vida y la cultura no con términos perentorios ni absolutos, sino con la amplitud de la calidad mortal.

Algo del actual caos debió incidir en su alma: llegó, poco a poco, a la inutilidad de todo. A fuerza de oír, seguramente, cómo nuestros hombres adjudican trascendencia hasta a las más insignificantes minucias cotidianas, él fué restándosela a todo. Sabía tanto... En estos días, leyendo a Paul Claudel, hemos escrito varias veces el nombre de Becher; en su Ballade dice el poeta católico: 
"Il faut garder notre connaissance pour nous, comprenant, comme une chose donnée dont l'on a d'un coup jouissance, -L'inutilité de l'homme pour l'homme et le mort en celui qui se croit vivant".

Pero Emilio Becher fué más lejos. En primer lugar, no hizo lo que Claudel: sentarse a escribir acerca de la inutilidad del hombre para el hombre; en segundo lugar, escogió el único camino posible cuando se ha llegado a esos términos de negación: la muerte. Porque los últimos años de Becher son un suicidio terrible y doloroso. Odiaba el alcohol, que le hacía un daño inmenso, y sin embargo, al alcohol se entregó con la aparente calma del escéptico y la real premura del solitario. Un momento levantó la frente, durante la Primera Guerra Mundial, para apostrofar la barbarie invasora. Estuvo, naturalmente, con la libertad y la justicia. Fué la única ocasión en que escribió con la fiereza del relámpago. ¡Pobre Becher! También él peleó en vano. Su agudeza analítica lo abandonó al enfocar la contienda. Creyó, como la mayoría, que la guerra era un conflicto moral y espiritual entre naciones, entre pueblos. No alcanzó a ver lo que recién nosotros, hacia 1950, veríamos, a saber: que la guerra la hacen los pueblos, pero la provocan y la impulsan cuatro o siete señores que viven dándoles la espalda a los pueblos, y que éstos, como cantó Martín Fierro, son los primeros en la guerra y nada ganan en la paz. ¡Pobre Becher! ¡Pobre inteligencia! „Pobre ideal!

$$
* *
$$

Una casualidad nos trajo a Becher. Fué, por remate, en el extranjero, si extranjeras pueden considerarse para los argentinos las hospitalarias y hermosas tierras de Chile. Edmundo Concha Contreras, uno de los espíritus mejor templados entre los escritores chilenos, nos puso frente a Becher a raíz de una conversación ocasional, de características polémicas. Concha Contreras sostenía una tesis cuya 
formulación se nos ha extraviado en los días. En todo caso, Emilio Becher iba a llegar para apoyarlo en ella. Pero después que hubimos leído Caín ya nada importó. La presencia de un alma superior volvía insignificantes nuestros puntos de vista. Estábamos ante un ser del cual teníamos mucho que aprender y casi nada con qué pagar; porque, se nos ocurre, con alguna tristeza en la prevención, que nuestra vocación poética es bien poca cosa ante la inmensidad de Emilio Becher. Un sólo remordimiento - ¿vanidad, tal vez? - nos asaltó entonces: no haber conocido antes a Becher. En ese momento tuvimos la impresión de que jamás habíamos leído a nadie que escribiera tan bien como nuestro autor. Al releerlo, al estudiarlo mil veces, la impresión se nos hizo certeza. No descartamos, en defensa de esta seguridad, que nuestro juicio está quizás socorrido por cierta misteriosa afinidad de vibración entre el autor y el lector. Pero esto nos sabe a soberbia.

¡Caso raro! De otros escritores o artistas connacionales hemos sentido orgullo. De Sarmiento, por ejemplo. No un orgullo simplista, sino el bien comprensible de que el grado cultural de nuestro pueblo haya logrado producir un genio tal. Pero de Becher no. De Becher no nos ha preocupado este sentimiento en forma alguna. Tal vez, una vaga tristeza, una melancolía muy suave. Es que Becher no nos pertenece con exclusividad. Becher no representa el pensamiento argentino, o lo representa pero además de otras cosas. Becher es el síntoma -el síntoma superior, que es ya en sí mismo la culminación- del cosmopolitismo afincado en Buenos Aires. Es, sí, un fruto de nuestra Capital, de nuestro rostro (un rostro lavado muy apresuradamente), pero no de nuestra realidad interior. Becher es la resultante dolorosa y bella de un largo proceso cuya raíz está en Francia y cuya desembocadura no podemos prever. Su refinamiento, su incisivo análisis, la pulcritud de su ironía, el orden perfecto de su discurso, la solemne claridad de su exposición no pueden provenir sino de una mentalidad ajustada con método a las seculares normas francesas de pensar. Unicamente a una inteligencia así educada 
le era dable descubrir en Sarmiento las mismas facetas espirituales de Facundo Quiroga, sólo que dirigidas al bien y a la creación, es decir, cultivadas.

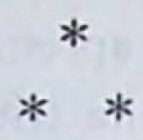

Sustancialmente, Emilio Becher cometió dos errores en su vida: uno, expresarse con furia acerca de los enemigos de la democracia liberal; el otro, imaginar que la victoria aliada era cuanto le quedaba por ver para morir en paz.

La furia desvirtúa la ironía y debilita al propio escritor, aunque le asista la verdad. Es la calma estilística de Becher lo que nos subyuga. Becher enfurecido deja de corresponder a su temperamento, deja de pensar bien. Tener pasiones es honroso patrimonio, siempre que no se hable apasionadamente, porque el corazón desbordado nunca deja de caer en la grandilocuencia. No es la pasión quien debe expresarse, sino la razón suscitada por aquélla. Ya se sabe que la pasión sin razones es un barco sin brújula, y que la razón sin pasiones es un rey sin súbditos.

En cuanto a lo del triunfo de los aliados... Se engañó Becher. Y a nosotros nos queda la esperanza de que él, posteriormente, haya tenido conciencia de su equívoco. La vida, la vida individual —única que tiene valor para el espíritu, pues sólo ella contiene el misterio-, vale más que todas esas victorias, aliadas o no, pues ella es la verdadera victoria y no debe rendírsela sino ante la certeza de la degradación. Becher sabía esto. Fué uno de los espíritus más individualistas que se han dado en nuestro suelo. Su religiosidad, su anticientifismo lo confirman. Amó el vuelo por sobre todas las cosas, y negó los consejos, las moralejas, las anécdotas: todo cuanto presupuestara cánones más o menos susceptibles de invalidar el razonamiento y el sentimiento de cada cual. Nunca nadie, ni siquiera Mark Twain, dejó tan mal puesto al pedestrismo vanidoso y ramplón de Benjamín 
Franklin, cuya exégesis conservaremos a título de ejemplar defensa de los valores espirituales.

No tiene, pues, trascendencia la afirmación de Becher. El ya había escogido la muerte mucho antes de que se vislumbrara la de. rrota alemana. En realidad, nuestro escritor había ya comenzado a morir años antes de que estallara la guerra.

Murió joven porque vivió intensamente. A los treinta años había hecho casi todo el camino. Fué un ejemplo de precocidad. Nos recuerda, en ese sentido, a Rimbaud. Pero, más valiente que Rimbaud, antes que hundirse en la burocracia ni en ninguna otra actividad extraña, remató dignamente su soledad. Tendióse en su cama del sanatorio, antes de la cena, y una falla del corazón vino en su ayuda. Cuando don Jorge A. Mitre, director de La Nación, lo supo, envió el siguiente telegrama al diario, telegrama que es en sí mismo un verdadero epitafio:

"Que el cuerpo de Becher sea velado por la presencia acongojada de sus compañeros y la luz inextinguible de su espíritu, y que ésta resplandezca en una página del diario como un holocausto, una enseña y un recuerdo".

Emilio Becher había ingresado a La Nación por virtud de una sencilla carta en la que aseguraba no haber tomado jamás antes la pluma ni haber redactado nunca nada. En esa época, el periodismo argentino tenía hombres de talento, verdaderos periodistas, y se sabía entrever virtudes.

Leopoldo Lugones cantó para Becher "el verso sencillo y conmovido... que conviene a tu alma como el vaso a la flor". Lo lloraron todos, sinceramente, como al hermano mayor. En esa época se lloraba con sinceridad a los muertos, sobre todo si eran ilustres.

José María Salaverría habría de decir, en un artículo que envió a La Nación y que luego insertaría en su libro Retratos, donde el de Becher toma plaza junto a los de Unamuno y Ortega Gasset: 
"Cuando una obra en la que hemos puesto el mayor afán de perfección queda terminada, instintivamente nuestro pensamiento evoca un nombre. Nos preguntamos: ¿Qué pensará él de esto que acabo yo de producir...? Tales personas forman el verdadero público, el positivo tribunal de nuestras creaciones. Generalmente no son numerosos los espíritus a quienes confiamos la censura de nuestras obras; a veces no es más que uno. $Y$ al hablar de obras se entiende que lo mismo pueden ser las perfeccionadas concepciones de un pensador o un artista, como el útil trabajo del menestral. En suma: el verdadero público lo llevamos dentro de nosotros, como un fantasma que nuestra inquietud creadora hace surgir en el fondo de nuestra conciencia. De modo que, en realidad, producimos siempre para un "alguien".

"Yo confieso que durante una larga temporada ese "alguien”, ese censor o fantasma familiar para quien yo escribía, fué Emilio Becher. Terminada la labor, caliente e inédita todavía la obra, la pregunta secreta saltaba al punto: “¿Qué pensará "él" de esto... ?" Pero debe prevenirse que en este fenómeno de complicada sugestión no interviene un bajo interés de vanidad. Por lo regular, el pudor nos impide solicitar una opinión expresa de "nuestro" alguien. Hay entre "él" y nosotros una mística asociación ideal demasiado elevada para que osemos pervertirla con groseras familiaridades.

"Abrí el periódico, vi el retrato del amigo a dos columnas y toda el alma se nubló de tristeza. ¡Se acabó... ! Ya no existe la fuerte y luminosa inteligencia que estaba asistida, milagrosamente, por un corazón dulce, por un carácter delicado".

Esta franqueza inteligente del gran prosista español contiene el homenaje que nosotros, aunque deseosos, no sabemos manifestar. Por su densa claridad, Becher, en efecto, puede ser el maestro del más inspirado hombre dispuesto a traducir en palabras su pensamiento. 


$$
\text { * * }
$$

Su amigo íntimo, Ricardo Rojas, lo lloró sin decirle nada. Mucho tiempo después habría de redactar unas páginas, con motivo de la edición, por la Facultad de Filosofía de la Universidad de Buenos Aires, de las Obras de Becher. No es extraño que Rojas sintiera a su dolor superior a las palabras. Nosotros mismos, que hemos aprendido a amar a Emilio Becher sólo a través de su estilo, de sus maravillosos artículos, hemos tomado la pluma cien veces antes de pergeñar estos débiles párrafos, que solamente tratan de ser, al fin de cuentas, el anticipado homenaje de admiración y cariño que un día, el propicio, debe rendirle la cultura argentina. 